\title{
Development of bark-based adhesives for plywood: utilization of flavonoid compounds from bark and wood. II
}

\author{
Tomoyuki Matsumae ${ }^{1 *}$, Masayoshi Horito ${ }^{1}$, Naoko Kurushima ${ }^{1}$ and Yoshikazu Yazaki ${ }^{2}$
}

\begin{abstract}
Although many conventional adhesives for plywood are formulated with tannins (polyflavanoid compounds) extracted from bark or wood, adhesives using tannin directly without extraction from the bark have also been made. In 2003, the first bark particle $(<63 \mu \mathrm{m})$ adhesive was developed from radiata pine bark. In this present study, the quality of the bark adhesive has been improved by fibrillating the bark. Finely ground bark was fibrillated using a disc mill and formulated into plywood adhesives, which consisted of fibrillated bark, phenol-formaldehyde (PF) resin and water in different ratios. The gluability of the fibrillated bark adhesives was evaluated according to the Japanese Agricultural Standard for Plywood (JAS) and was found to be excellent. These bark adhesives have a number of advantages in that there is no tannin extraction, there is a total use of the bark, a low-level requirement of PF resins, no other components required and there is a high glue bond quality. Considering that very small amounts of fibrillated bark adhesives produced high-quality wood bonding, the bark components such as tannin, hemicellulose, lignin, cellulose nanofibers and other components may well be contributing to produce such a good bonding.
\end{abstract}

Keywords: Pinus radiata bark, Radiata tannin, Polyflavanoids, Fibrillated bark, Plywood adhesives

\section{Introduction}

The flavonoid compounds, which have been used commercially, are tannins derived from barks and woods. One of the most commonly used tannins is wattle tannin, which is obtained as a hot water extract from the bark of black wattle (Acacia mearnsii De Wild.) [1, 2]. As reported in the early history of Australia, Acacia mearnsii bark was first identified in 1814 as one of the excellent sources of tannins for the tanning of leather and a textile factory was opened at Botany Bay in New South Wales in 1815 with a tannery established before 1820 [3].

The major components of wattle tannin are polyflavanoids consisting of flavan-3-ols as monomers and their polymers. Although the use of wattle tannin in leather tanning commenced in the early 1820 s, the commercial use of wattle tannin as a major component in the

\footnotetext{
*Correspondence: tomoyuki.matsumae@woodone.co.jp ${ }^{1}$ WOOD ONE Co., Ltd, 1-12-1, Shimohera, Hatsukaichi-shi, Hiroshima 738-0023, Japan

Full list of author information is available at the end of the article
}

manufacture of wood adhesives commenced only in the middle of the 1960s. Details of the historical development of tannin adhesives for use in structural and external application wood products and a new approach to the use of the tannin in the bark without extraction, which was described as "bark adhesives" from radiata pine, were reported in 2015 [1].

Unlike the rapid industrial acceptance and the largescale commercial use of wattle tannin adhesives for more than 50 years, the commercial use of tannin adhesives derived from radiata tannin, which is extracted from the bark of radiata pine (Pinus radiata D. Don), has not been realized, except for a small industrial particleboard and medium-density fiberboard (MDF) production and trials in Chile lasting approximately 15 years [4].

In the normal use of tannins in wood adhesives, the tannins have to be extracted from bark or wood using water as the solvent. However, an attempt has been made to use tannins directly without extracting them from the bark. This was based on the discovery that a fine particle fraction $(<63 \mu \mathrm{m})$ of radiata pine bark contained up 
to $70 \%$ tannin. Therefore, a technology to use the tannin in the finely ground bark particles without extraction has been developed for the production of wood adhesives [5]. A plywood adhesive has been formulated with bark par-

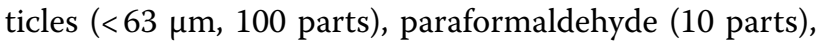
water (165 parts) and a small amount of aqueous sodium hydroxide to adjust the $\mathrm{pH}$ to 8 . However, paraformaldehyde is not desired for factory use due to its toxicity and the quality of the formulations was found to be quite variable. Therefore, formulations producing a better quality of wood adhesives were required.

Since early 2000, interest has been focused on the use of wood as a renewable resource for the purpose of resolving the problem of depleting fossil resources and research is being conducted that attempts to extract cellulose nanofibers from wood. Since cellulose nanofibers have demonstrated superior properties such as light weight, high strength and low thermal expansion, they are attracting considerable attention for use in next-generation industrial materials [6-8]. Attempts to obtain cellulose nanofibers from bark have been reported only from the bark of lodgepole pine (Pinus contorta) in Canada [9, 10]. However, the authors of that study were not interested in the tannins contained in the lodgepole pine bark, but actually removed the tannins from the bark as part of their investigation. Since radiata pine bark contains significant amounts of procyanidin polymers (polyflavanoids), which consist of linear chains of $3^{\prime}, 4^{\prime}$-dihydroxy flavan-3-ol units that have undergone varying degrees of condensation as shown in Fig. 1 [11-13], radiata pine bark was fibrillated using a disc mill and formulated into plywood adhesives. The gluability of the fibrillated bark adhesives was evaluated according to the Japanese Agricultural Standard for Plywood (JAS) [14] and found to be excellent; the details of this newly developed technology using fibrillated bark as a constituent of the adhesives are described below together with the technology of using fine bark particles in the adhesive.

\section{Materials and methods}

\section{Radiata pine bark}

The bark used was obtained from 30- to 35-year-old radiata pine logs (Pinus radiata D. Don) from Kaitaia in New Zealand and collected from debarkers. It was dried at $100{ }^{\circ} \mathrm{C}$ for $24 \mathrm{~h}$, and then sent to WOOD ONE CO., LTD. in Hiroshima, Japan.

\section{Sample preparation}

\section{Bark particles $(<63 \mu \mathrm{m})$}

The dried radiata pine bark was roughly ground using a garden shredder, and then further size reduced using a hammer mill having a screen opening of $1 \mathrm{~mm}$. The fine bark was classified using a sieve having a sieve opening of

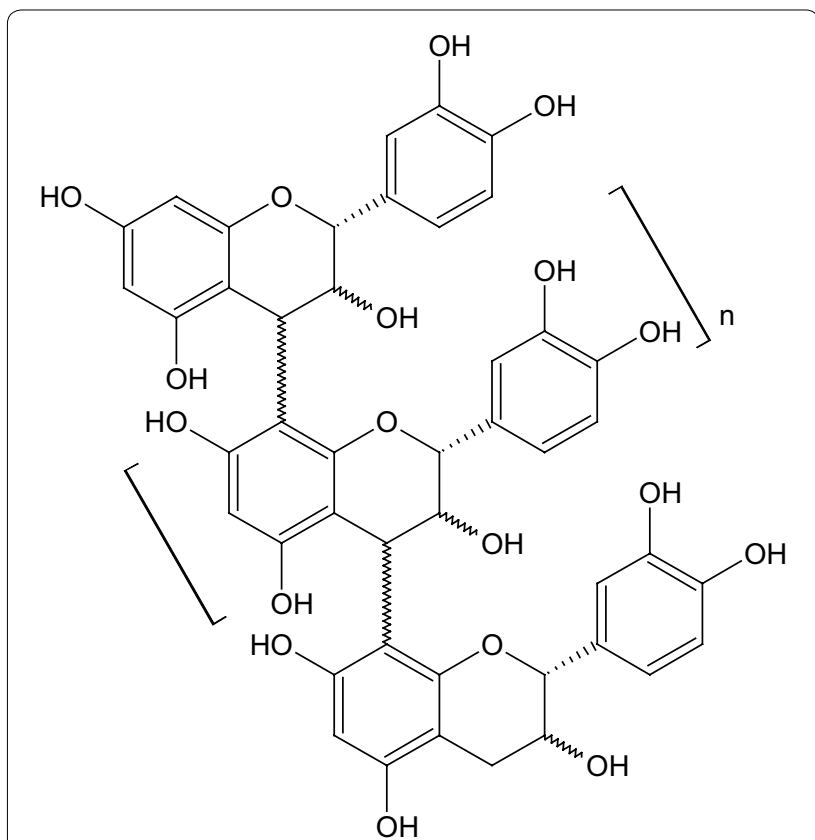

Fig. 1 Structure of procyanidin polymers contained in radiata tannin

$63 \mu \mathrm{m}$, and bark passing through the screen that is having a particle size of $63 \mu \mathrm{m}$ or less was used in the adhesion tests.

\section{Fibrillated bark}

Bark particles $(<63 \mu \mathrm{m}, 1 \mathrm{~kg})$ were soaked in water $(10 \mathrm{l})$ for $24 \mathrm{~h}$ and then fibrillated using a disk mill (Supermasscolloider MKZA10-15J; MASUKO SANGYO CO., LTD., Japan) at $1800 \mathrm{rpm}$. Bark slurry was fed continuously to the disk mill consisting of two grinding disks positioned on top of each other. The fibrillation was operated at contact grinding with the gap between the two disks decreasing from 80 to $0 \mu \mathrm{m}$ at the end. The fibrillated bark was collected after 10 passes and then freeze-dried.

\section{Phenol-formaldehyde (PF) resins}

The PF resins used were commercially available resins. PF resin A and PF resin B were used for the experiments of the bark particle adhesives and the fibrillated bark adhesives, respectively. The properties of these PF resins are shown in Table 1.

\section{Adhesives formulations}

Formulations, total solids contents and viscosities of the adhesives are shown in Tables 2 and 3. Bark particle adhesives were prepared by mixing the bark particles $(<63 \mu \mathrm{m})$ with a PF resin A and wheat flour at a solids content ratio as shown in Table 2. Fibrillated bark 
Table 1 Properties of PF resins

\begin{tabular}{|c|c|c|}
\hline & PF resin A & PF resin $B$ \\
\hline Solids content (\%) & 44.7 & 44.8 \\
\hline Viscosity (Pa.s) $\left(23^{\circ} \mathrm{C}\right)$ & 0.24 & 0.33 \\
\hline $\mathrm{pH}^{1}$ & 13.5 & 11.3 \\
\hline Gelation time $(\mathrm{min})\left(100^{\circ} \mathrm{C}\right)^{1}$ & $31-44$ & 24 \\
\hline \multicolumn{3}{|l|}{ Molecular weight ${ }^{2}$} \\
\hline Number-average molecular weight (Mn) & 2050 & 1237 \\
\hline Weight-average molecular weight (Mw) & 12,317 & 2993 \\
\hline Polydispersity (Mw/Mn) & 6.01 & 2.42 \\
\hline
\end{tabular}

${ }^{1}$ Catalogue spec

2 The molecular weight was determined by measuring the acetylated phenolic resin by gel permeation chromatography (GPC)

adhesives were prepared by mixing the fibrillated bark with a PF resin B at a solids content ratio as shown in Table 3. The viscosity of each adhesive was adjusted by adding water as shown in these tables.

\section{Gluing conditions}

Gluing conditions for plywood production were not optimized for each adhesive, but were set at these conditions on the assumption that the adhesive would completely cure. Three-ply plywood samples were prepared by bonding radiata pine veneers $(250 \mathrm{~mm} \times 250 \mathrm{~mm} \times 3 \mathrm{~mm})$ conditioned to $4 \%$ moisture content. Each of the adhesives was applied at a spread rate of $200 \mathrm{~g} / \mathrm{m}^{2}$ in a single glue line. The spread panels were prepressed at room temperature at $1.0 \mathrm{MPa}$ for $30 \mathrm{~min}$. All panels were then pressed at $135^{\circ} \mathrm{C}$ at $1.0 \mathrm{MPa}$ for $10 \mathrm{~min}$.

\section{Assessment of bonding quality}

The assessment of the bonding quality was made according to the criteria for the adhesive bonding level of "Type special" as defined in the JAS [14]. "Type special" is the type of plywood the main purpose of which is for use outdoors or in places (environments) where conditions are continuously wet. The plywood samples were tested according to the "Continuous Boiling Test" defined in the JAS. Bonding strength tests on all specimens were carried out in the wet state after 72-h immersion in boiling water and the average of shear strength and average wood failure ratio determined. The bonding quality was regarded as "PASS" if shear strength (MPa) and average wood failure ratio (\%) were not less than the values in the following combinations: $0.7 \mathrm{MPa}-$ (no limit)\%, 0.6 $\mathrm{MPa}-50 \%$, $0.5 \mathrm{MPa}-65 \%$ and $0.4 \mathrm{MPa}-80 \%$.

\section{General methods}

The extraction of radiata tannin and the determination of the adjusted Stiasny values and polyflavanoid contents of the extracts have been described previously

Table 2 Bark particle adhesive composition and bonding quality from the continuous 72-h boiling test (JAS)

\begin{tabular}{|c|c|c|c|c|c|}
\hline Adhesives $^{1}$ & CF-A & $1-1$ & $1-2$ & $1-3$ & $1-4$ \\
\hline \multicolumn{6}{|l|}{ Mass ratio } \\
\hline PF resin (solids) & 100 & 70 & 60 & 60 & 50 \\
\hline Bark particles & 0 & 30 & 40 & 28 & 35 \\
\hline Wheat flour & 36 & 0 & 0 & 12 & 15 \\
\hline Other solid components & 36 & 0 & 0 & 0 & 0 \\
\hline Total solids content (\%) & 55 & 40 & 37 & 40 & 35 \\
\hline Viscosity $(\mathrm{Pa} \cdot \mathrm{s})\left(23^{\circ} \mathrm{C}\right)$ & 3.2 & 2.0 & 2.7 & 2.2 & 1.8 \\
\hline $\mathrm{pH}^{3}$ & nd & nd & nd & nd & nd \\
\hline Gelation time $(\min )\left(135^{\circ} \mathrm{C}\right)^{3}$ & nd & nd & nd & nd & nd \\
\hline \multicolumn{6}{|l|}{ Reactive components in adhesive (\%) } \\
\hline PF resin contents & 32.2 & 28.0 & 22.2 & 24.0 & 17.5 \\
\hline Polyflavanoids contents & 0.0 & 5.1 & 6.2 & 4.7 & 5.2 \\
\hline \multicolumn{6}{|l|}{ Bonding test results } \\
\hline Number of panels & 4 & 3 & 4 & 5 & 4 \\
\hline Number of specimens & 32 & 24 & 28 & 40 & 32 \\
\hline Average of shear strength $(\mathrm{MPa})^{2}$ & $1.06 \pm 0.35^{a}$ & $0.83 \pm 0.12^{b c}$ & $0.95 \pm 0.19^{a b}$ & $1.00 \pm 0.22^{a b}$ & $0.77 \pm 0.20^{c}$ \\
\hline Average wood failure ratio $(\%)^{2}$ & $80.0 \pm 22.7^{a}$ & $28.3 \pm 25.5^{b}$ & $59.3 \pm 27.9^{\mathrm{a}}$ & $68.3 \pm 29.9^{a}$ & $70.6 \pm 22.0^{\circ}$ \\
\hline Judgment of test results (JAS) ${ }^{4}$ & PASS & PASS & PASS & PASS & PASS \\
\hline
\end{tabular}

\footnotetext{
1 "CF-A" means "Commercial formulation A" and refers to the formulation of a commercial adhesive for plywood using PF resin $A$

${ }^{2}$ Results are given as the mean \pm standard deviation. ANOVA showed that the means are significantly different $(p<0.001)$. Means having the same letter (a, b, $\left.c\right)$ within a row are not significantly different as determined by the Tukey's test $(p<0.05)$

3 "nd" means "not determined"

4 "PASS" means met the criteria of JAS
} 
Table 3 Fibrillated bark adhesive composition and bonding quality from the continuous 72-h boiling test (JAS)

\begin{tabular}{|c|c|c|c|c|c|c|c|}
\hline Adhesives $^{1}$ & CF-B & $2-1$ & $2-2$ & $2-3$ & $2-4$ & $2-5$ & $2-6$ \\
\hline \multicolumn{8}{|l|}{ Mass ratio } \\
\hline PF resin (solids) & 100 & 70 & 60 & 50 & 40 & 30 & 20 \\
\hline Fibrillated bark & 0 & 30 & 40 & 50 & 60 & 70 & 80 \\
\hline Wheat flour & 22 & 0 & 0 & 0 & 0 & 0 & 0 \\
\hline Other solid components & 48 & 0 & 0 & 0 & 0 & 0 & 0 \\
\hline Total solids content (\%) & 55 & 39 & 33 & 30 & 27 & 24 & 21 \\
\hline Viscosity $(\mathrm{Pa} \cdot \mathrm{s})\left(23^{\circ} \mathrm{C}\right)$ & 1.4 & 3.1 & 2.5 & 2.7 & 3.1 & 2.2 & 2.8 \\
\hline $\mathrm{pH}$ & 11.8 & 10.8 & 10.3 & 9.9 & 9.6 & 9.1 & 8.3 \\
\hline Gelation time $(\min )\left(135^{\circ} \mathrm{C}\right)$ & 9.5 & 8.0 & 7.0 & 5.5 & 7.0 & 9.0 & 9.5 \\
\hline \multicolumn{8}{|l|}{ Reactive components in adhesive (\%) } \\
\hline PF resin contents & 32.0 & 27.3 & 19.8 & 15.0 & 10.8 & 7.2 & 4.2 \\
\hline Polyflavanoids contents & 0.0 & 6.2 & 6.9 & 7.9 & 8.5 & 8.9 & 8.9 \\
\hline \multicolumn{8}{|l|}{ Bonding test results } \\
\hline Number of panels & 4 & 4 & 4 & 4 & 3 & 4 & 4 \\
\hline Number of specimens & 32 & 32 & 32 & 25 & 24 & 31 & 32 \\
\hline Average of shear strength $(\mathrm{MPa})^{2}$ & $0.84 \pm 0.21^{b}$ & $1.04 \pm 0.28^{\mathrm{a}}$ & $1.13 \pm 0.30^{\mathrm{a}}$ & $0.74 \pm 0.15^{b}$ & $0.71 \pm 0.13^{b}$ & $0.74 \pm 0.24^{b}$ & $0.70 \pm 0.13^{b}$ \\
\hline Average wood failure ratio $(\%)^{2}$ & $87.2 \pm 9.9^{\mathrm{a}}$ & $89.1 \pm 15.5^{\mathrm{a}}$ & $90.9 \pm 13.3^{\mathrm{a}}$ & $72.0 \pm 33.3^{\mathrm{a}}$ & $32.5 \pm 35.3^{b}$ & $21.9 \pm 25.6^{b}$ & $27.8 \pm 28.6^{b}$ \\
\hline Judgment of test results (JAS) ${ }^{3}$ & PASS & PASS & PASS & PASS & PASS & PASS & PASS \\
\hline
\end{tabular}

1 "CF-B" means "Commercial formulation B" and refers to the formulation of a commercial adhesive for plywood using PF resin B

2 Results are given as the mean \pm standard deviation. ANOVA showed that the means are significantly different $(p<0.001)$. Means having the same letter (a, b) within a row are not significantly different as determined by the Tukey's test $(p<0.05)$

3 "PASS" means met the criteria of JAS

$[11,13,15]$, although hot methanol was used as the solvent for the tannin extraction.

The viscosity of each of the adhesives was determined at $23{ }^{\circ} \mathrm{C}$ using a coaxial cylinder rotational viscometer (HAAKE Viscotester 550 (VT 550); Thermo Electron Co., Germany) with a SV-DIN type measuring system.

The solids content (\%) of the adhesives was calculated using the equation indicated as follows:

\section{Solids content (\%) $=$ (weight after drying/ weight before drying) $\times 100$.}

The gelation time $\left(135^{\circ} \mathrm{C}\right)$ and the $\mathrm{pH}$ of adhesives were determined in accordance with Japanese Industrial Standard (JIS) K 6807 "General testing methods of formaldehyde resin adhesives for wood" [16].

The fibrillated bark was examined using a field emission scanning electron microscope (SEM) (JSM7800F Prime; JEOL Ltd., Japan) at the Research Institute for Sustainable Humanosphere, Kyoto University, Uji, Kyoto. The fibrillated bark slurry was solventexchanged with $t$-butyl alcohol and freeze-dried. The dried bark samples were vacuum coated with platinum before the SEM observations were undertaken.

\section{Statistical analysis}

The data obtained from the bonding quality test (shear strength and wood failure) were analysed, respectively, by one-way analysis of variance (ANOVA) and Tukey's test. The statistical analyses were performed using the $R$ open-source statistical software package (version 3.5.1; R Development Core Team, Austria).

\section{Results \\ Gluing properties \\ Bark particle $(<63 \mu \mathrm{m})$ adhesives}

Adhesives 1-1 and 1-2 were formulated to give mass ratios of PF resin (solids) to bark particles of 70:30 and 60:40, respectively, whilst Adhesives 1-3 and 1-4 contained PF resin, bark particles and wheat flour. The mass ratios of PF resin (solids), bark particles and wheat flour were 60:28:12 and 50:35:15, while a constant mass ratio of the bark particles to wheat flour was maintained at 7:3. The plywood samples were bonded with Adhesives 1-1 to 1-4 and their gluing properties were assessed under the continuous 72-h boiling test in accordance with JAS. The composition, properties of the adhesives and the results from these continuous 72 -h boiling tests are summarized in Table 2.

The ratios of PF resin (solids), bark particles $(<63 \mu \mathrm{m})$ and water in Adhesives 1-1 to 1-4 are shown in Fig. 2. All 


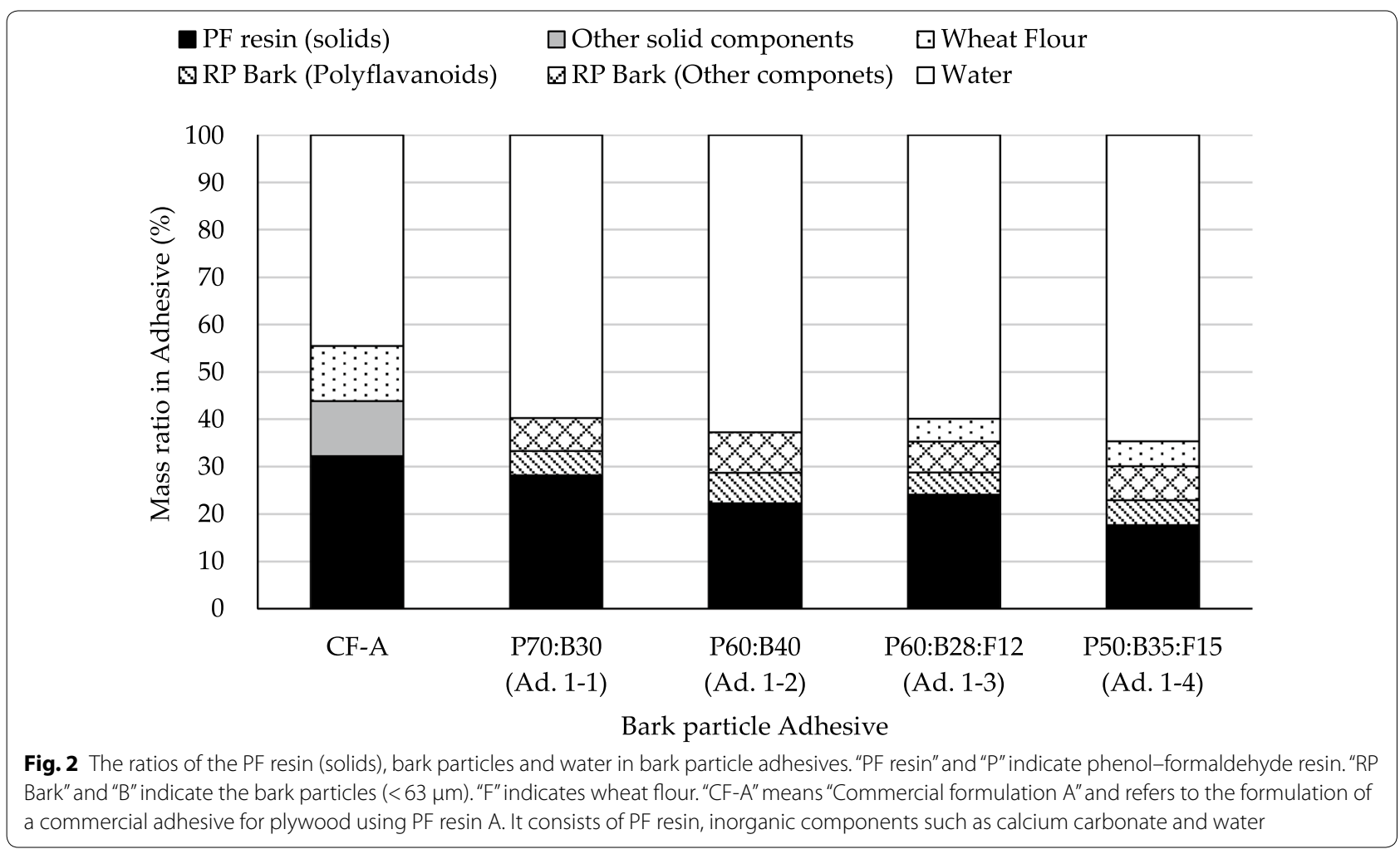

Adhesives 1-1 to 1-4 achieved excellent bonding quality namely "PASS" on the JAS criteria, despite the lower total solids contents (35-40\%), compared to those of commercial PF resin adhesive formulations (ca. 55\%) named as Commercial formulation A (CF-A). In the results of the shear strength and the wood failure ratio, the standard deviations were high, since the results differ depending on whether the loading direction and lathe check direction were forward or reverse. The results of statistical analysis both on shear strength and wood failure ratio showed that Adhesives 1-2 and 1-3 were not significantly different from CF-A $(p<0.05)$. The results showed that Adhesives 1-2 and 1-3 were similar in both the shear strength and the average of wood failure ratio to commercial adhesive CF-A.

The results shown in Table 2 confirmed that the Adhesives 1-2 and 1-3 formulations which contain 60, 40, 0 and 60, 28, 12 parts by mass of PF resin (solids), bark particles and wheat flour, provided excellent glue bonding similar to commercial adhesive CF-A and that the adhesives which contain 30-40 parts by mass of the bark particles also provided very good glue bonding, which satisfied the requirements of the JAS for exterior use of plywood.

\section{Fibrillated bark adhesives}

Fibrillated bark adhesives were formulated with only PF resin and fibrillated bark in which the mass ratios of the
$\mathrm{PF}$ resin to the fibrillated bark ranged from 70:30 (Adhesive 2-1) to 20:80 (Adhesive 2-6). Bonding quality (shear strength and wood failure ratio) of plywood samples, which were bonded with these adhesives, were assessed again using the JAS continuous 72-h boiling tests for plywood adhesives. The adhesive composition and results from the 72-h boiling tests are summarized in Table 3.

The ratios of PF resin (solids), fibrillated bark and water in Adhesives 2-1 to 2-6 are shown in Fig. 3. The solids contents of the PF resin of Adhesives 2-1 to 2-6 were reduced from a mass ratio of 70 to 20 with the amount of fibrillated bark increased from a mass ratio of 30 to 80. The solids content of Adhesives 2-1 to 2-6 decreased from 39 to $21 \%$. However, even with the low total solids content compared to those of commercial PF resin adhesive formulations (ca. 55\%) named as Commercial formulation B (CF-B), the gluing properties of the adhesives were able to achieve a "PASS" on the basis of the JAS continuous 72-h boiling test. The standard deviations of the shear strength and the wood failure ratio were high. The results of statistical analysis both on shear strength and wood failure ratio showed that Adhesives 2-1 and 2-2 were significantly different from the other adhesives $(p<0.05)$. These results showed that Adhesive 2-1 and 2-2 were superior in both the shear strength and the average of wood failure 


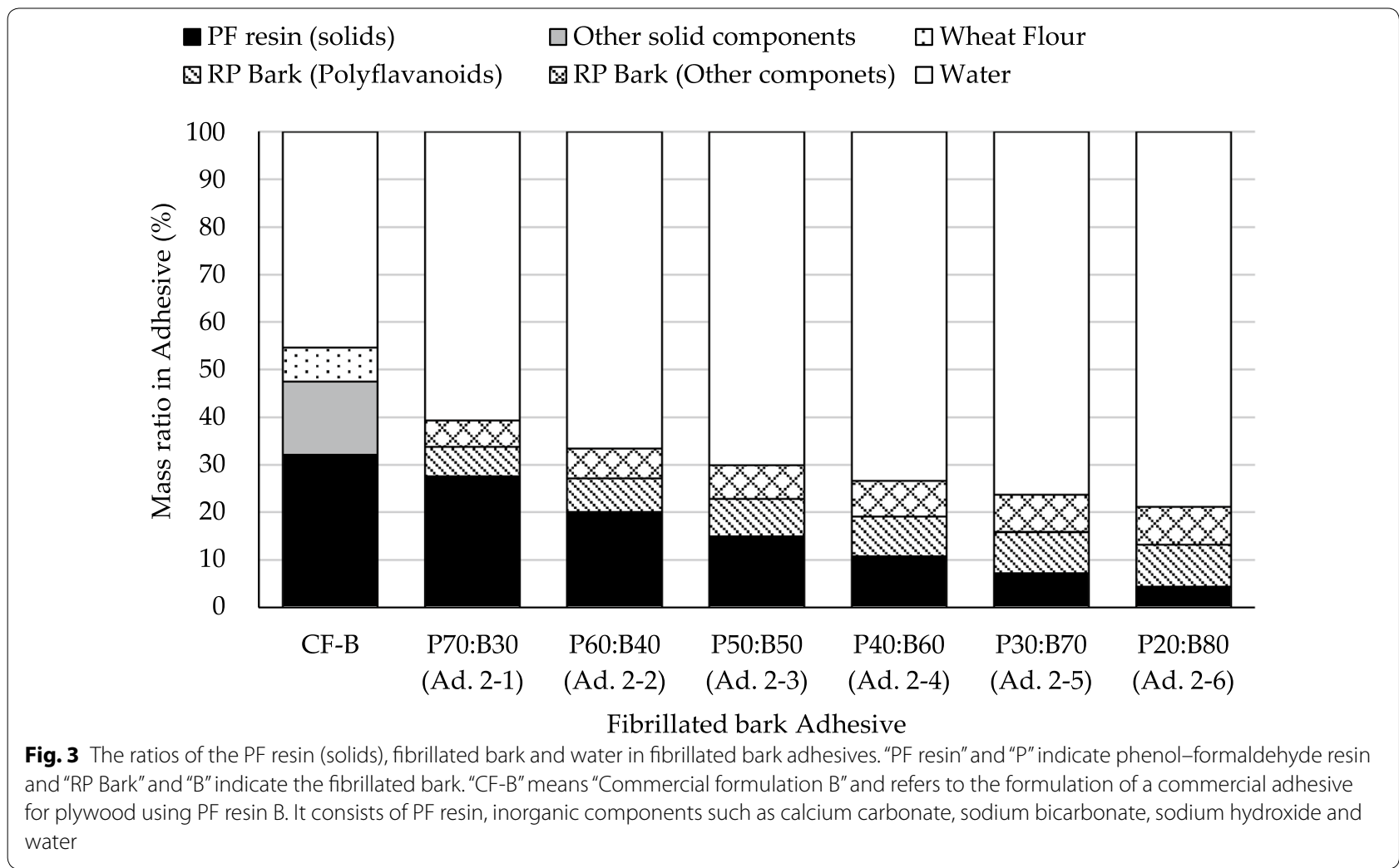

Table 4 Comparison of bark particle adhesives and fibrillated bark adhesives

\begin{tabular}{|c|c|c|c|c|c|c|c|c|c|c|c|c|}
\hline \multirow[t]{2}{*}{ Adhesives $^{1}$} & \multicolumn{5}{|c|}{ Bark particle adhesives } & \multicolumn{7}{|c|}{ Fibrillated bark adhesives } \\
\hline & CF-A & $1-1$ & $1-2$ & $1-3$ & $1-4$ & CF-B & $2-1$ & $2-2$ & $2-3$ & $2-4$ & $2-5$ & $2-6$ \\
\hline \multicolumn{13}{|l|}{ Bonding test results } \\
\hline Average of shear strength² & a & $b c d$ & $a b c$ & $a b$ & $\mathrm{~cd}$ & $b c d$ & a & a & $\mathrm{cd}$ & $d$ & $d$ & $d$ \\
\hline Average wood failure ratio ${ }^{2}$ & $a b c$ & d & $c$ & $b c$ & $a b c$ & $a b c$ & a & a & $a b c$ & $d$ & $d$ & $d$ \\
\hline Judgment of test results $(\mathrm{JAS})^{3}$ & PASS & PASS & PASS & PASS & PASS & PASS & PASS & PASS & PASS & PASS & PASS & PASS \\
\hline
\end{tabular}

1 "CF-A" and "CF-B" means "Commercial formulation A" and "Commercial formulation B", respectively

2 ANOVA showed that the means are significantly different $(p<0.001)$. The same letter $(a, b, c, d)$ within a row are not significantly different as determined by Tukey's test $(p<0.05)$

3 "PASS" means met the criteria of JAS

ratio to the other adhesives including CF-B, which was similar to Adhesive 2-3.

The results from the JAS continuous 72-h boiling test shown in Table 3 confirmed that adhesives containing 30-80 parts by mass of fibrillated bark provided excellent glue bonding.

\section{Comparison of bark particle adhesives and fibrillated bark adhesives}

In order to compare the bark particle adhesives and the fibrillated bark adhesives, a statistical analysis was conducted using the results from all 12 adhesives (Adhesives
1-1 to 1-4, Adhesives 2-1 to 2-6 and Commercial formulations). The results of the statistical analysis are summarized in Table 4. Tukey's test confirmed that there was a significant difference between Adhesives (2-1 and 2-2) and the other adhesives in both shear strength and wood failure $(p<0.05)$.

\section{Discussion}

\section{Bonding quality of adhesives}

The results of this study showed that both the bark particle adhesives and the fibrillated bark adhesives provided excellent glue bonding meeting the criteria of the JAS. 
In the bark particle adhesives, although all adhesives had sufficient bonding quality, that both shear strength and wood failure of the Adhesive 1-3 were higher than these properties found with Adhesives 1-2, 1-1 and 1-4. In the fibrillated bark adhesives, even with the low total solids content, the gluing properties of the adhesives were able to achieve a "PASS" on the basis of the JAS continuous 72-h boiling test. However, the results from the statistical analysis and the JAS tests showed that the best gluing properties were obtained with the Adhesives 2-1 and 2-2 when adhesives containing fibrillated bark were considered. Comparing the bark particle adhesives and fibrillated bark adhesives, Adhesives 2-1 and 2-2 showed the best performance among all ten adhesives (Adhesives 1-1 to 1-4 and 2-1 to 2-6). When the adhesives with the same blending ratio of PF resin and bark (Adhesives 1-1, 1-2 and 2-1,2-2), were compared, the performances of Adhesives 2-1 and 2-2 were found to be significantly better. When adhesives with the same PF resin content ratios in the adhesive (Adhesives 1-3 and 2-2) were considered, Adhesive 2-2 showed a better result.

This study showed that bark particle adhesives and fibrillated bark adhesives both gave excellent bonding qualities which satisfy the requirements of the JAS for exterior use of plywood, despite the fact that they contained low total solids contents. Adhesives containing fibrillated bark contained much lower total solids contents and were simple formulations in that they only contained PF resin, fibrillated bark and water.

The gluing conditions used in this study are our laboratory standard, which assesses the gluability of adhesives for plywood. The hot pressing time of $10 \mathrm{~min}$ at $135^{\circ} \mathrm{C}$ is quite a long time for a 3-layered plywood and would not be economic in commercial practice. The next stage in the study for the industrial application of bark adhesives will be to optimize the gluing conditions. We are confident that the 10-min hot pressing time can be substantially reduced.

\section{Amounts of reactive components and high-quality gluing properties}

In order to provide excellent gluing properties, it has been found in the reported studies that approximately $30 \%$ polyflavanoid content was required in the radiata tannin adhesives for plywood production, in which the total solids content was $47.4 \%[17,18]$. In comparison, the PF resin content of commercial PF resin adhesives is approximately $32 \%$ with the total solids content of approximately $55 \%$.

The polyflavanoid compounds react with formaldehyde and/or PF resins at higher temperatures, so that glue bonding can be made. The Stiasny value can provide an estimate of the total amount of polyflavanoids in the extract, which reacts with formaldehyde. However, the Stiasny values for purified tannins or tannin monomers (controls) are always higher than 100\% [19]. Therefore, the Stiasny values for tannin extracts must be divided by those of the controls, so that "adjusted Stiasny values" are obtained. The adjusted Stiasny values more accurately indicate the percentage of reactive polyflavanoids in the extracts, which react with formaldehyde in the adhesive formulation. The content of polyflavanoids in the bark can be calculated by multiplying the yield of tannin extract by its adjusted Stiasny value [15]. Since the yield of tannin extract and its adjusted Stiasny value for the fibrillated bark were $61.9 \%$ and $85.1 \%$, respectively, the content of polyflavanoids was $52.7 \%$, whilst the yield of tannin extract, the adjusted Stiasny value and the content of polyflavanoids for the bark particles $(<63 \mu \mathrm{m})$ were $46.2 \%, 91.2 \%$ and $42.1 \%$, respectively. Consequently, the polyflavanoid content in the total solids can be obtained by multiplying the total solids, the bark ratio and the content of polyflavanoids 0.421 (42.1\%) for the bark particles $(<63 \mu \mathrm{m})$ or $0.527(52.7 \%)$ for the fibrillated bark. For example, in the gluing trial using the bark particles adhesive 1-4 in Table 2, the total solids content of $35 \%$ in which PF resin, bark particles and wheat flour were 50\%, 35\% and $15 \%$, respectively. Therefore, the PF resin content is $17.5 \%$ and the polyflavanoid content $(35 \% \times 0.35 \times 0.421)$ is $5.2 \%$, the content of reactive components responsible for good gluing in Adhesive 1-4 was calculated to be $22.7 \%$. In the plywood gluing trial using the fibrillated bark adhesive 2-6 in Table 3, the total solids content is $21 \%$, in which the ratio of PF resin and the fibrillated bark is $20 \%$ and $80 \%$, respectively. Since the reactive components of PF resin and the fibrillated bark were $4.2 \%$ and $8.9 \%$, the amount of reactive components for good gluing was calculated to be only $13.1 \%$. The contents of reactive components (PF resin and polyflavanoid compounds) of the adhesives are shown in Tables 2 and 3.

Considering that the contents of reactive components (polyflavanoids) in radiata tannin adhesives $[17,18]$ and also in commercial PF resin adhesives are approximately $30 \%$, the amount of reactive components of $13.1 \%$ in the fibrillated bark adhesive (Adhesive 2-6) is small indeed. This strongly suggests that all the components in the fibrillated bark contribute to providing the excellent bonding properties. Chemical compositions of radiata pine bark are approximately $20 \%$ cellulose, $15 \%$ lignin, $7 \%$ hemicellulose, $30 \%$ neutral solvent extractives including tannin and 25\% phenolic acids ( $1 \% \mathrm{NaOH}$ solubles) [11]. Therefore, these components of the bark could play an important role in providing the high-quality plywood gluing.

An SEM image of the fibrillated bark is shown in Fig. 4. It was observed that nano-sized fibres having a diameter 


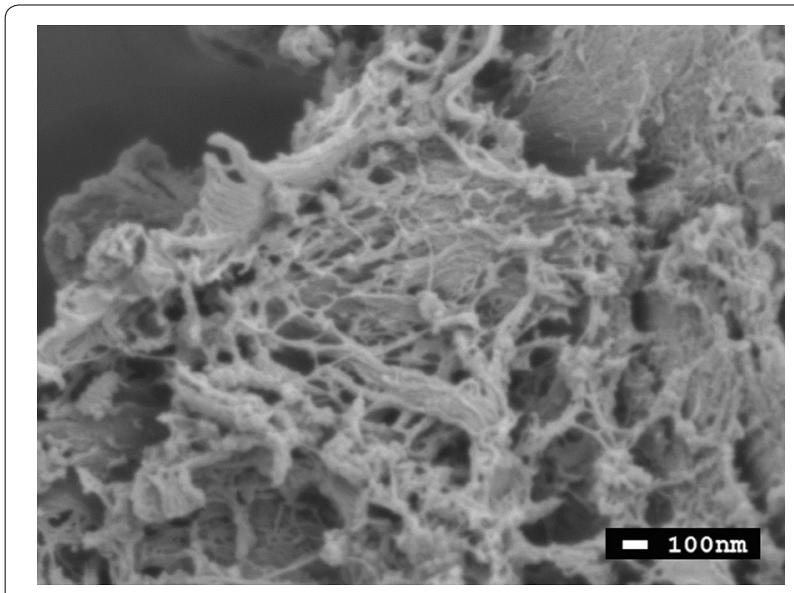

Fig. 4 SEM image of the fibrillated bark

of $40 \mathrm{~nm}$ or less existed in the fibrillated bark. These nano-sized fibres were presumed to be cellulose nanofibers formed from the disintegrated cell walls of the bark [20]. Since it has been reported that the addition of the cellulose nanofibers enhances physical and mechanical properties of plastics [6-8], it is suspected that the existence of cellulose nanofibers in the fibrillated bark adhesives enhances the glue bond quality. The roles of lignin and hemicellulose must be elucidated by future studies.

\section{Conclusions}

This study revealed for the first time that the gluability of fibrillated bark adhesives, which were formulated with PF resin, fibrillated bark and water only, gave excellent results despite optimum gluing conditions not being used. These fibrillated bark adhesives have a number of advantages in that there is no requirement for tannin extraction, there is a total use of bark, a low-level requirement of PF resins, no other components required and there is a high glue bond quality.

Considering the results from this study, small amounts of fibrillated bark adhesives, which contain a very small amounts of reactive components, produced high-quality wood bonding. This suggests that other bark components such as tannin, hemicellulose, lignin, cellulose nanofibers and other components may well be contributing to produce such a good bonding. Therefore, further study is required in order to find the bonding mechanisms for fibrillated bark adhesives.

These results suggest the possibility that fibrillated bark adhesives could be used not only for plywood production, but also for the other wood-based panels (fiberboard, particleboard, strand board, etc.), and so further research is anticipated.

\section{Abbreviations}

ANOVA: One-way analysis of variance; CF-A: Commercial formulation A refers to the formulation of commercial adhesive for plywood using phenol-formaldehyde resin $A ;$ CF-B: Commercial formulation B refers to the formulation of commercial adhesive for plywood using phenol-formaldehyde resin B; GPC: Gel permeation chromatography; JAS: Japanese Agricultural Standard for Plywood; JIS: Japanese Industrial Standards; MDF: Medium-density fiberboard; PF: Phenol-formaldehyde; SEM: Field emission scanning electron microscope.

\section{Authors' contributions}

$\mathrm{TM}, \mathrm{MH}$ and $\mathrm{YY}$ conceived and designed the experiments. MH performed the experiments and analysed the physical test data, and NK analysed chemical components. TM, MH, NK and YY wrote the paper. All authors read and approved the final manuscript.

\section{Author details}

${ }^{1}$ WOOD ONE Co., Ltd, 1-12-1, Shimohera, Hatsukaichi-shi, Hiroshima 738-0023, Japan. ${ }^{2}$ Department of Chemical Engineering, Monash University, Clayton, VIC 3800 , Australia.

\section{Acknowledgements}

The authors would like to thank Hiroyuki Yano at Research Institute for Sustainable Humanosphere, Kyoto University, for the SEM examination, Hidetaka Nogami at Okayama Prefectural Research Institute for Forest and Forest Products for producing fibrillated bark samples, Takashi Endo and Seiichi Inoue at National Institute of Advanced Industrial Science and Technology, Hiroshima for their valuable advice regarding the fibrillation of bark and Frank Lawson from Monash University for his critical reading of this manuscript.

\section{Competing interests}

The authors declare that they have no competing interests.

\section{Availability of data and materials}

All data generated or analysed during this study are included in this published article.

\section{Funding}

Not applicable.

\section{Publisher's Note}

Springer Nature remains neutral with regard to jurisdictional claims in published maps and institutional affiliations.

Received: 1 October 2018 Accepted: 30 December 2018

Published online: 22 February 2019

\section{References}

1. Yazaki Y (2015) Utilization of flavonoid compounds from bark and wood: a review. Nat Prod Commun 10(3):513-520

2. Ogawa S, Yazaki Y (2018) Tannins from Acacia mearnsii. De Wild. bark: tannin determination and biological activities. Molecules 23(4):837. https:// doi.org/10.3390/molecules23040837

3. Searle S (1991) The rise and demise of the black wattle bark industry in Australia. Technical paper No. 1, CSIRO Division of Forestry, Australia

4. Valenzuela J, von Leyser E, Pizzi A, Westermeyer C, Gorrini B (2012) Industrial production of pine tannin-bonded particleboard and MDF. Eur J Wood Prod 70(5):735-740

5. Nakamoto Y, Tsunoda T, Ono K, Yano H, Yazaki Y, Jian H, Lawson F, Uhlherr PHT (2011) A method for the production of powder with high tannin content and its use (in Japanese). JP Patent 4683258

6. Moon RJ, Martini A, Nairn J, Simonsen J, Youngblood J (2011) Cellulose nanomaterials review: structure, properties and nanocomposites. Chem Soc Rev 40:3941-3994

7. Isogai A (2013) Wood nanocelluloses: fundamentals and applications as new bio-based nanomaterials. J Wood Sci 59(6):449-459

8. Nakagaito AN, Yano H (2014) Cellulose-nanofiber-based materials. In: Hinestroza JP, Netravali AN (eds) Cellulose based composites: new green nanomaterials. Wiley-VCH, Weinheim, pp 3-25 
9. Nair SS, Yan N (2015) Effect of high residual lignin on the thermal stability of nanofibrils and its enhanced mechanical performance in aqueous environments. Cellulose 22(5):3137-3150

10. Nair SS, Yan N (2015) Bark derived submicron-sized and nano-sized cellulose fibers: from industrial waste to high performance materials. Carbohydr Polym 134:258-266

11. Yazaki Y (1985) Extraction of polyphenols from Pinus radiata bark. Holzforschung 39(5):267-271

12. Yazaki Y, Hillis WE (1977) Polyphenolic extractives of Pinus radiata bark. Holzforshung 31(1):20-25

13. Yazaki Y, Hillis WE (1980) Molecular size distribution of radiata pine bark extracts and its effect on properties. Holzforschung 34(4):125-130

14. Japanese Agricultural Standard (2014) Japanese Agricultural Standard (JAS) for Plywood (in Japanese), Notification No. 303 of the Ministry of Agriculture, Forestry and Fisheries of Japan. Japan Plywood Inspection Corporation, Tokyo, Japan

15. Yazaki Y, Morita S, Collins PJ (1998) Potential use of Acacia mangium bark for water-proof wood adhesives. In: Proceedings of the fourth pacific rim bio-based composites symposium, Bogor, Indonesia, 2-5 November 1998. pp 36-44
16. Japanese Industrial Standards (JIS) K6807 (2012) General testing methods of formaldehyde resin adhesives for wood (in Japanese). Japanese Standards Association, Tokyo

17. Yazaki Y, Collins PJ (1994) Wood adhesives from Pinus radiata bark. Holz Roh-Werkst 52(3):185-190

18. Yazaki Y, Collins PJ (1998) A novel tannin extraction from Radiata pine bark for high quality wood adhesives. In: Proceedings of the fourth pacific rim bio-based composites symposium, Bogor, Indonesia, 2-5 November 1998. pp 19-26

19. Saito N, Reilly M, Yazaki Y (2001) Chemical structures of (+)-catechinformaldehyde reaction products (Stiasny precipitates) under strong acid conditions. Part 1 Solid-state 13C-NMR Analysis. Holzforshung 55(2):205-213

20. Abe K, Nakatsubo F, Yano H (2009) High-strength nanocomposite based on fibrillated chemi-thermomechanical pulp. Compos Sci Technol 69(14):2434-2437

\section{Submit your manuscript to a SpringerOpen ${ }^{\odot}$ journal and benefit from:}

- Convenient online submission

- Rigorous peer review

- Open access: articles freely available online

- High visibility within the field

- Retaining the copyright to your article

Submit your next manuscript at $\boldsymbol{\nabla}$ springeropen.com 